\title{
Colonialidade e Crítica Social: Análise da Música “Índios” Legião Urbana 1986
}

\author{
La colonización y la crítica social: Análisis de la música "Indios" Legión \\ Urbana 1986
}
Coloniality and Social Criticism: Analysis of the Music "Indians" Urban Legion 1986

\section{Cleber Rocha de Oliveira ${ }^{1}$}

\begin{abstract}
Resumo
A presente pesquisa pretende uma análise da música "Índios" produzida e lançada pela banda brasileira Legião Urbana em meados de 1986. As proposições criticas de cunho social inseridas na letra desta música permitiram uma construção histórica onde o processo de colonização, subjugação e encobrimento do "Outro" o indígena são apresentados de forma reflexiva ao público alvo no caso os jovens brasileiros da década de 80. Como proposição metodológica para análise dessa obra nos propomos a dialogar com duas produções historiográficas: a primeira são os escritos de Ledezma, Gerson. Racismo o colonialidad del saber en la Historiografía brasileña, de Francisco Varnhagen a Gilberto Freyre e a segunda a obra de Quijano, Aníbal. Cuestiones y Horizontes: De la Dependencia Histórico-Estructural a la Colonialidad/ Descolonialidad del Poder.
\end{abstract}

Palavras-chave: Legião Urbana; Índios; Colonialidade.

\section{Resumen}

La presente investigación pretende un análisis de la música "Indios" producida y lanzada por la banda brasileña Legión Urbana a mediados de 1986. Las proposiciones criticas de cuño social insertadas en la letra de esta canción permitieron una construcción histórica donde el proceso de colonización, subyugación y encubrimiento del "Otro" el indígena es presentado de forma reflexiva al público objetivo en el caso los jóvenes brasileños de la década de 80. Como proposición metodológica para analizar esa obra nos proponemos a dialogar con dos producciones historiográficas la primera son los escritos de Ledezma, Gerson. Racismo o Colonialidad del saber en la Historiografía brasileña, de Francisco Varnhagen a Gilberto Freyre y la segunda la obra de Quijano, Aníbal. Cuestiones y Horizontes: De la Dependencia Histórico-Estructural a la Colonialidad / Descolonialidad del Poder.

Palavras claves: Legión Urbana; Indios; Colonialidad.

\begin{abstract}
The present research intends an analysis of the music "Indians" produced and launched by the Brazilian band Legião Urban in the middle of 1986. The critical social propositions inserted in the lyrics of this song allowed a historical construction where the process of colonization, subjugation and cover- Another "indigenous" are presented in a reflective way to the target audience in the case the young Brazilians of the 80's. As a methodological proposal for the analysis of this work we propose to dialogue with two historiographic

\footnotetext{
${ }^{1}$ Historiador e Mestrando no Programa de Pós-Graduação Interdisciplinar em Estudos Latino-Americanos. PPGIELA - Projeto produzido sob orientação do professor Dr. Gerson Galo Ledezma Meneses, Universidade Federal da Integração Latino Americana - UNILA, Foz do Iguaçu, Paraná, Brasil; Cleber.oliveira@aluno.unila.edu.br.
} 
productions. The first is the writings of Ledezma, Gerson. Racism or Coloniality of knowledge in the Brazilian Historiography, Francisco Varnhagen Gilberto Freyre and the second the work of Quijano, Hannibal. Issues and Horizons: From the Historical-Structural Dependence to Coloniality / Decoloniality of Power.

Keywords: Urban Legião; Indians; Coloniality.

\section{O Rock nacional e a formação dos movimentos sociais de 1980}

O Brasil da década de 1980 seguindo a vertente norte americana e inglesa do "Rock and Roll” de meados de 1960 e 70 se tornou palco de grande influência musical, onde abordagens com perspectivas critico sociais começaram a ganhar notoriedade e espaço na esfera social brasileira.

A ditadura militar que atuava no país desde 1964 começou a se desestabilizar durante a década de 80 essa reviravolta política aliada a instável situação econômica do país permitiram a ascensão de bandas de rock que de certa forma transmitiam o desagrado social em suas produções musicais voltadas para o público jovem.

Os valores da democracia perdidos durante as décadas de regime militar começam a surgir estampados nas entrelinhas de músicas produzidas por diversas bandas de "rock punk" no Brasil, dentre elas com maior repercussão social estavam Aborto Elétrico, Plebe Rude e Distrito Federal, essas por sua vez após a crescente repercussão e ascensão do rock no país favoreceram o surgimento após 1982 de outras como Paralamas do Sucesso, RPM, Legião Urbana e Capital Inicial.

Essas bandas desafiavam um sistema ditatorial que imprimia uma forte censura aos meios de comunicação (televisão, rádio, cartazes, musicas, etc.) desde 1964, esse desafiar começou a dar lugar a coragem do povo, principalmente ao público jovem, a crítica social depositada na letra de várias músicas produzidas encorajou vários movimentos sociais compostos em sua grande maioria por jovens na luta contra a esfera política-repressiva que atuava no Brasil.

Nesse contexto do surgimento de levantes sociais contra o governo ditatorial é que surgem novas bandas de rock com reformulações e propostas critico sociais ainda mais ferrenhas contra o aparato politico do país, produções com engajamento e cunho revolucionário ganham notoriedade e espaço na sociedade brasileira, a busca por soluções aos problemas econômicos, político e sociais do país ganhava a cada dia mais força e 
consistência, o rock nacional se tornou uma ferramenta que impulsionava a sociedade brasileira na luta por direitos e liberdade de expressão.

As letras musicais de várias bandas de rock nacional permitiam uma forte crítica e reflexão acerca do retrospecto político, econômico e social que o país se encontrava, na grande maioria as letras imprimiam um espírito de mudança (Revolucionário) transmitiam os anseios do povo, a necessidade de mudanças onde a corrupção, a privação da liberdade de expressão e desigualdade social pudessem ser combatidas, mas não somente isso, várias letras ainda permitiam uma reflexão acerca da formação histórica da sociedade brasileira desde o processo de colonização aos dias atuais, pois somente compreendendo a formação da nossa sociedade é que poderíamos nos permitir a novas e pertinentes mudanças.

$\mathrm{O}$ anseio social desses jovens em prol de mudanças acabou impulsionando um movimento político conhecido por "Diretas Já" que surgiu entre 1983 a 1984, esse movimento reivindicava eleições presidenciais diretas no Brasil feito que acabou sendo concretizado posteriormente e acabou se tornando símbolo da luta contra o sistema repressivo que atuava no país.

Essa reflexão acerca da influência e impacto do movimento do rock nacional na sociedade brasileira se faz necessária para compreendermos o histórico das produções musicais que ocorreram nesse período, a letra da música "Índios" da Banda Legião Urbana lançada em 1986 não se difere de outras tantas produções produzidas nesse mesmo período, o impacto social da música "Índios" também foi significativo na esfera social dos jovens brasileiros.

Carregada de uma profunda reflexão histórica esta música busca uma construção crítica acerca da formação da sociedade brasileira, ela permite uma análise de elementos significativos que influenciaram na formação da sociedade atual permitindo ao publico alvo refletir acerca dos problemas enfrentados no na década de 1980 e relaciona-los com a formação colonial do país desde 1500.

A produção da música "índios" tem sua autoria direcionada ao cantor, poeta e músico Renato Manfredini Junior (1960-1996) conhecido como Renato Russo o poeta que mobilizava multidões, Renato ficou conhecido por ter uma carreira artística tumultuada cheia de altos e baixos, passou por conturbados períodos depressivos, com crises psicológicas, o envolvimento com as drogas e a posterior descoberta da contaminação por HIV, mas suas produções artísticas tinham o poder de mobilização social arrebatadora. 
Figura I

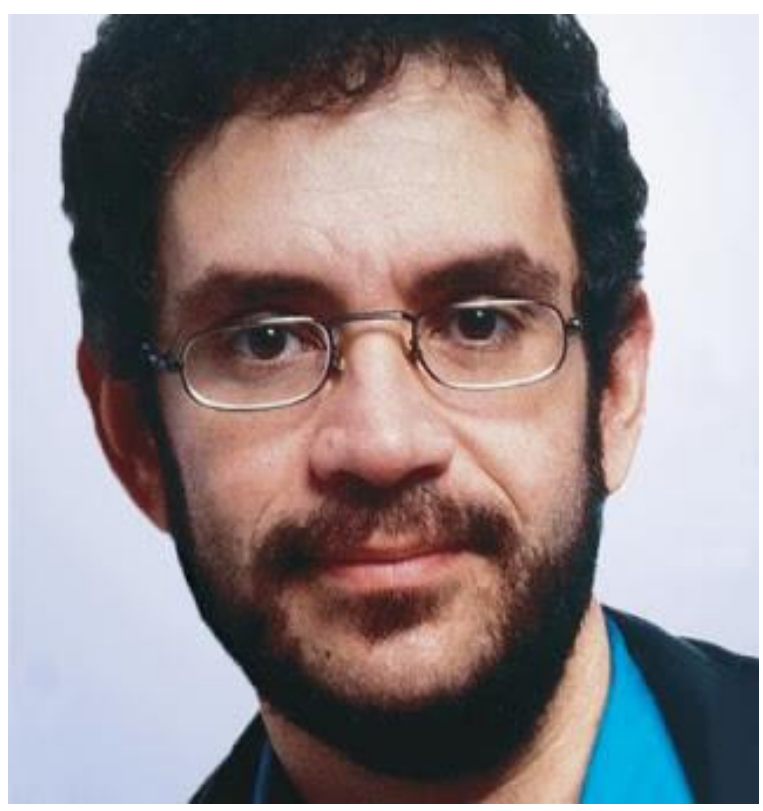

Renato Manfredini Junior, (Renato Russo), disponível em: http://teatroemcena.com.br (Pesquisado em $22 / 11 / 2017)$

Renato Russo se tornou após a formação da banda Legião Urbana em 1982 porta voz da juventude brasileira, diante de insatisfações sociais que se apresentavam no país naquele período, ele conseguia mobilizar movimentos sociais que reflexionavam acerca de questões pontuadas em suas composições, a insatisfação com o sistema político, econômico e social do país era facilmente captada pelo público que tinha acesso a suas produções autorais. Isso influenciou uma grande leva de movimentos que tinham como ponto de partida reinvindicações que iam de encontro as críticas levantadas por Renato Russo em suas autorias.

O fato é que Renato Russo conseguiu articular uma grande influência na estrutura interna da sociedade nacional, suas músicas abordavam as dificuldades e o cotidiano das pessoas que se encaixavam perfeitamente nos anseios da juventude brasileira, foi esse um dos fatores que tornaram Renato Russo um dos artistas mais influentes do país nesse período

Uma composição de Renato de 1986 é o objeto de pesquisa desse projeto, a análise da música "Índios" de 1986 permite contemplarmos um pouco dos argumentos critico-reflexivos que as músicas produzidas pelo cantor apresentavam ao seu público.

\section{Legião Urbana e a música "Índios"}


Nesta pesquisa nos propomos analisar trechos da música produzida por Renato Russo (1986) música esta que nos permite uma reflexão histórica acerca de acontecimentos que refletiram e refletem ainda hoje na formação da sociedade brasileira, os trechos da música analisados nesta obra não seguem uma ordem cronológica e sim uma contextualização histórica e reflexiva acerca de sua produção, no final de toda a análise dos trechos pontuados na pesquisa a letra da música estará disponibilizada integralmente seguindo sua produção original (Anexo).

Iniciamos a análise da música com um trecho que permite um retorno ao processo de colonização do Brasil.

Quem me dera ao menos uma vez / Ter de volta todo o ouro que entreguei a quem / Conseguiu me convencer que era prova de amizade / Se alguém levasse embora até o que eu não tinha. (LEGIÃO URBANA, 1986).

Nesta parte da música observamos uma questão reflexiva acerca do ouro roubado durante o processo de conquista e colonização do Brasil, Renato Russo nos permite refletir acerca do ouro roubado dos indígenas que se iniciou através de um saque a essas terras, após a chegada dos portugueses.

As promessas malfeitas "prova de amizade" para conquistar a confiança dos nativos que aqui habitavam, portugueses trocavam espelhos e quinquilharias em troca de informações onde se localizava o ouro dessas terras, a formação do Brasil se deu através de um processo mentiroso onde a confiança com os nativos foi comprada e após subjugada e escravizada, a colonialidade do poder sobre os nativos e a imposição de seu poderio foram as marcas deixadas pelos conquistadores.

De acordo com Ledezma e Guanaes (2017, p.22) as colonialidades do poder, do saber e do ser foram redirecionadas para exterminar ou dominar regiões, culturas, saberes, territórios ancestrais e outros espaços construídos durante o regime colonial, elementos tidos como opositores ao estabelecimento do Estado nacional que deveria ser moderno, patriarcal e ainda colonial, negros e indígenas nesse processo eram tidos como inferiores (bárbaros) todo o processo de conquista da América portuguesa se deu através de uma perspectiva sócio cultural dominante.

Um segundo trecho da música trata exatamente a questão do poder na ocupação da América portuguesa 
Quem me dera ao menos uma vez / Esquecer que acreditei que era por brincadeira / Que se cortava sempre um pano-de-chão / De linho nobre e pura seda. (LEGIÃO URBANA, 1986).

Renato busca pontuar neste trecho elementos impositivos da superioridade imposta pelos portugueses, um indígena de fato não saberia diferenciar o linho nobre e pura seda de um pano de chão, pois a inocência e a perplexidade dos nativos diante do choque cultural com outra sociedade foi imensurável, para os portugueses os indígenas não passavam de povos inferiores e ignorantes a eles só cabia a sujeição aos brancos europeus.

Os europeus tanto na América portuguesa como espanhola impuseram um sistema de superioridade do ser, do saber e do poder sem precedentes, de acordo com Quijano ( 2014, p. 14). A colonialidade do poder condiciona toda a existência social das gentes de todo o mundo, já que a racionalização delimita de modo decisivo o lugar de cada pessoa ou povo nas relações de poder global, mas foi na América sobretudo a Latina que se fez mais evidente e traumática a diferenciação entre índios, negros, brancos e mestiços.

Renato conseguia apresentar fielmente essa imposição social na composição em sua música, apresentando ao seu público, a crueldade que foi imposta aos nativos durante a conquista da América portuguesa, esse processo deixou profundas marcas em nossa sociedade, e está de fato enraizado em uma estrutura patriarcal de subjugação social no caso a de imposição de elementos de uma cultura sobre as outras consideradas eurocentricamente como "culturas inferiores".

Em outro trecho da música podemos observar a descrição de um mundo doente.

Quem me dera ao menos uma vez / Que o mais simples fosse visto / Como o mais importante / Mas nos deram espelhos e vimos um mundo doente. (LEGIÃO URBANA, 1986).

Os conquistadores não trouxeram somente a ambição por riquezas para o "Novo Mundo" trouxeram mazelas sociais, um mundo doente, as doenças dizimaram os indígenas esse é o mundo doente ao qual Renato cita.

É interessante como o poeta aborda as trocas comerciais dos portugueses com os nativos, pois foram nelas que se iniciaram as falsas promessas de alianças amigáveis, esse foi somente o primeiro passo no processo de exploração destas terras, após esse primeiro contato amigável vieram as opções forçadas a subjugação e escravização dos nativos na busca por riquezas para alimentar as regalias da Coroa portuguesa que provinham do Novo Mundo. 
De acordo com Ledezma e Guanaes (2016, p. 24) O aparato colonial não se interessou em captar e aplicar o conceito de cultura como o projetou um dos precursores da Antropologia Franz Boas que pregava um convite a uma visão relativa das culturas. O aparato colonial interessou apenas em colocar em prática o projeto de civilização o qual tinha como escopo a transformação das culturas indígenas em dóceis mestiços alienados, consumidores e dependentes mentalmente do sistema, tudo foi imposto, desde a herança sociocultural, civilizatória, econômica, até a religiosa em um forçado processo de imposição cultural.

A imposição religiosa aos nativos pode ser percebida no próximo trecho a ser pontuado.

Quem me dera ao menos uma vez / Entender como um só Deus ao mesmo tempo é três / E esse mesmo Deus foi morto por vocês / Sua maldade, então, deixaram Deus tão triste. (LEGIÃO URBANA, 1986).

Neste ponto da música Renato polemiza a questão de Deus segundo a perspectiva religiosa cristã, como os nativos poderiam entender a perspectiva cristã de Deus se nunca tiveram contato com essa estrutura cultural europeia, a catequização forçada dos indígenas durante o processo de colonização só contribuiu para com o desmantelamento de grandiosas estruturas sociais.

Para os indígenas os trovões, as chuvas o crescimento de árvores e fartura nos rios, eram frutos de deuses e não de um único Deus como então impor essa concepção de forma diferente do que sempre foi passado de geração após geração através da oralidade, não existiria outro modo a não ser através da imposição cultural.

Existiu um desprezo por parte dos portugueses quanto a cultura dos povos nativos que aqui habitavam, a inocência e o modo de vida edênico ao qual os indígenas aqui disfrutaram anterior ao descobrimento não mais serio o mesmo após a chegada da Naus a essas terras.

Neste próximo trecho podemos observar a menosprezo cultural para com as sociedades nativas

Quem me dera ao menos uma vez / Como a mais bela tribo / Dos mais belos índios / Não ser atacado por ser inocente. (LEGIÃO URBANA, 1986).

Renato tenta mostrar ao público como seria bom se a mais belas das tribos, dos mais belos índios, de saberes naturais e culturais imensuráveis, passados de gerações a gerações não fosse atacada por ser inocente por não compreender o estigma sócio cultural eurocêntrico, 
não serem atacados simplesmente por não se enquadrar no modelo europeu de civilização sócio cultural.

Os portugueses privaram os indígenas de qualquer tipo de pensamento, sentimento, comunicação e sociabilidade, o pensamento foi reprimido, o sentimento imposto, a comunicação combatida e a sociabilidade dilacerada, os mais diversos métodos de imposição sociocultural foram impostos aos indígenas a eles somente restou a adaptação a esse repressivo sistema colonial, através de muitos séculos esse processo de repetiu

Nos deram espelhos e vimos um mundo doente / Tentei chorar e não consegui. (LEGIÃO URBANA, 1986).

Renato Russo finaliza a letra de sua música refletindo novamente acerca dos espelhos que serviam de moeda em troca da indicação de lugares que poderiam ter ouro para os portugueses, deram espelhos e quinquilharias aos indígenas em troca de tudo, se aproveitaram da inocência dos nativos em benefício próprio, mas mesmo com tamanha destruição e desestruturação interna das sociedades nativas Renato tem esperanças.

\section{Conclusão}

Através de muitos séculos esse processo conhecido como colonialidade do poder, do ser e saber foi reproduzido e readaptado, a sociedade brasileira assim como muitas outras sociedades da América Latina aprendeu a reproduzir fielmente esse mesmo processo de imposição cultural sobre as classes inferiores, os sujeitos se alteraram, mas o princípio de subjugação continua o mesmo, patriarcal, machista, eurocêntrico e individualista.

Cabe a sociedade que busca mudanças e perspectivas revolucionárias refletir acerca dessa reprodução presente desde o processo de colonização, como ser igualitário diante dos mais diversos anseios sociais, a resposta para isso está na descolonização de práticas arcaicas onde só há espaço para alguns e não para todos.

O que Renato Russo queria de fato com a reprodução desta música era apresentar ao público uma noção do que é necessário combater para que uma sociedade igualitária possa surgir, o problema da sociedade brasileira não está na atualidade está na herança nas raízes que o processo colonizador deixou para ela.

Somente podemos obter uma sociedade mais justa e digna se agirmos com igualdade social acima de tudo e sob todos os aspectos, esse é o primeiro passo de uma desconstrução decolonial significativa onde, brancos, negros, indígenas, mestiços, gays, lésbicas, entre outros possam compartilhar a mesma esfera social sem imposições sejam elas culturais, político, sociais ou religiosas, Renato Russo pregou essa igualdade em todos os Shows que 
realizou com a Banda Legião Urbana na década de 80 talvez esse seja um dos maiores legados do homem que impulsionava multidões em prol de suas causas.

\section{Anexos}




\begin{tabular}{|c|c|}
\hline \multicolumn{2}{|c|}{ LEGIÃO URBANA (1986) "ÍNDIOS" } \\
\hline Quem me dera, ao menos uma vez & Eu quis o perigo e até sangrei sozinho. \\
\hline Ter de volta todo o ouro que entreguei & Entenda - assim pude trazer você de volta prá mim \\
\hline A quem conseguiu me convencer & Quando descobri que é sempre só você \\
\hline Que era prova de amizade & Que me entende do início ao fim \\
\hline Se alguém levasse embora até o que eu não tinha & E é só você que tem a cura para o meu vício \\
\hline & De insistir nessa saudade que eu sinto \\
\hline Quem me dera, ao menos uma vez & De tudo que eu ainda não vi. \\
\hline Esquecer que acreditei que era por brincadeira & \\
\hline Que se cortava sempre um pano-de-chão & Quem me dera, ao menos uma vez \\
\hline De linho nobre e pura seda & Acreditar por um instante em tudo que existe \\
\hline & E acreditar que o mundo é perfeito \\
\hline Quem me dera, ao menos uma vez & E que todas as pessoas são felizes. \\
\hline Explicar o que ninguém consegue entender & \\
\hline Que o que aconteceu ainda está por vir & Quem me dera, ao menos uma vez \\
\hline E o futuro não é mais como era antigamente & Fazer com que o mundo saiba que seu nome \\
\hline & Está em tudo e mesmo assim \\
\hline Quem me dera, ao menos uma vez, & Ninguém lhe diz ao menos obrigado \\
\hline Provar que quem tem mais do que precisa ter & \\
\hline Quase sempre se convence que não tem o bastante & Quem me dera, ao menos uma vez \\
\hline E fala demais por não ter nada a dizer & Como a mais bela tribo, dos mais belos índios \\
\hline & Não ser atacado por ser inocente \\
\hline Quem me dera, ao menos uma vez & \\
\hline Que o mais simples fosse visto como o mais & Eu quis o perigo e até sangrei sozinho \\
\hline importante & Entenda - assim pude trazer você de volta prá mim \\
\hline Mas nos deram espelhos & Quando descobri que é sempre só você \\
\hline E vimos um mundo doente & Que me entende do início ao fim \\
\hline & E é só você que tem a cura para o meu vício \\
\hline Quem me dera, ao menos uma vez & De insistir nessa saudade que eu sinto \\
\hline Entender como um só Deus ao mesmo tempo é três & De tudo que eu ainda não vi \\
\hline E esse mesmo Deus foi morto por vocês & \\
\hline É só maldade então, deixar um Deus tão triste & Nos deram espelhos e vimos um mundo doente \\
\hline & Tentei chorar e não consegui \\
\hline
\end{tabular}




\section{Referências}

LEDEZMA, Gerson. Racismo o colonialidad del saber en la historiografía brasileña, de Francisco Varnhagen a Gilberto Freyre, Revista de Ciencias Sociales y humanidades, Vol II, Quito, Equador, 2017.

LEDEZMA, Gerson. Colonialidad del Saber : historia e historiografía brasileña (reflexiones desde Abya-Yala). In: XAVIER, Lídia de Oliveira, et. Al. POLÍTICA, CULTURA E SOCIEDADE NA AMÉRICA LATINA: estudos interdisciplinares e comparativos, Volume 3. Curitiba, 2016.

QUIJANO, Aníbal. CUESTIONES Y HORIZONTES: De la Dependencia Histórico-Estructural a la Colonialidad/Descolonialidad del Poder, 1ed. -Ciudad Autónoma de Buenos Aires: CLACSO, 2014. 